\title{
Somatic Depolarization Enhances GABA Release in Cerebellar Interneurons via a Calcium/Protein Kinase C Pathway
}

\author{
Brice Bouhours, Federico F. Trigo, and Alain Marty \\ Laboratoire de Physiologie Cérébrale, Centre National de la Recherche Scientifique and Université Paris Descartes, 75006 Paris, France
}

In cortical and hippocampal neurons, tonic somatic depolarization is partially transmitted to synaptic terminals, where it enhances transmitter release. It is not known to what extent such "analog signaling" applies to other mammalian neurons, and available evidence concerning underlying mechanisms is fragmentary and partially controversial. In this work, we investigate the presence of analog signaling in molecular layer interneurons of the rat cerebellum. GABA release was estimated by measuring autoreceptor currents in single recordings, or postsynaptic currents in paired recordings of synaptically connected neurons. We find with both assays that moderate subthreshold somatic depolarization results in enhanced GABA release. In addition, changes in the calcium concentration were investigated in the axon compartment using the calcium-sensitive dye OGB-1 (Oregon Green BAPTA-1). After a step somatic depolarization, the axonal calcium concentration and the GABA release probability rise with a common slow time course. However, the amount of calcium entry that is associated to one action potential is not affected. The slow increase in calcium concentration is inhibited by the $\mathrm{P} / \mathrm{Q}$ calcium channel blocker $\omega$-agatoxin-IVA. The protein kinase C inhibitor Ro 31-8220 (3-[3-[2,5-dihydro-4-(1-methyl-1H-indol-3-yl)-2,5dioxo-1H-pyrrol-3-yl]-1H-indol-1-yl]propyl carbamimidothioic acid ester mesylate) did not affect the calcium concentration changes but it blocked the increase in GABA release. EGTA was a weak blocker of analog signaling, implicating a close association of protein kinase $\mathrm{C}$ to the site of calcium entry. We conclude that analog signaling is prominent in cerebellar interneurons and that it is triggered by a pathway involving activation of axonal $\mathrm{P} / \mathrm{Q}$ channels, followed by calcium entry and local activation of protein kinase $\mathrm{C}$.

\section{Introduction}

It is well known that the probability of neurotransmitter release at a synapse critically depends on the past activity of the presynaptic neuron ("short-term synaptic plasticity"). This does not only concern past action potentials but also subthreshold potential changes. In invertebrate preparations, it was shown long ago that subthreshold presynaptic depolarization enhances transmitter release (Shimahara and Tauc, 1975; Nicholls and Wallace, 1978). A similar effect was recently demonstrated in synaptically connected cortical pyramidal cells (Shu et al., 2006). Simultaneous axonal and somatic recordings from cortical or hippocampal neurons revealed a substantial spread of subthreshold potentials from the soma to presynaptic terminals that reflects the passive membrane properties of the axon cable (Alle and Geiger, 2006; Shu et al., 2006). In these examples, the cable length constant of

Received Sept. 30, 2010; revised Feb. 8, 2011; accepted Feb. 16, 2011.

Author contributions: B.B., F.F.T., and A.M. designed research; B.B. and F.F.T. performed research; B.B. and F.F.T. analyzed data; B.B. and A.M. wrote the paper.

This work was supported by a fellowship from the French Ministry of Research (B.B.), by Agence Nationale pour la Recherche Contract 08-231083, and by a grant from Fondation pour la Recherche Médicale (A.M.). We thank Joël Chavas for performing preliminary experiments showing an involvement of cytosolic GABA concentration in washout, Isabel Llano for help with the two-photon recording, and Brandon Stell for help with the fast CCD camera imaging experiments. We also thank Isabel Llano and Brandon Stell for their comments on this manuscript.

Correspondence should be addressed to Alain Marty, Laboratoire de Physiologie Cérébrale, Centre National de la Recherche Scientifique and Université Paris Descartes, 45 rue des Saints Pères, 75006 Paris, France. E-mail: alain.marty@parisdescartes.fr.

DOI:10.1523/JNEUROSCI.5127-10.2011

Copyright $\odot 2011$ the authors $\quad 0270-6474 / 11 / 315804-12 \$ 15.00 / 0$ the axon is on the order of $500 \mu \mathrm{m}$. Since the distance between the soma and synaptic terminals of brain synapses is often much less than this value, these results suggest that many other cases of such "analog signaling" may exist in the mammalian brain.

The notion that subthreshold somatodendritic synaptic potentials can modulate the strength of subsequent transmitter release has deep implications on the mechanisms of information processing in the brain (Alle and Geiger, 2008). However, it is not known whether analog signaling is specific of the few preparations studied so far or whether it is a general phenomenon. Likewise, the underlying mechanism remains uncertain. In the cortex, depolarization-induced changes in the shape of presynaptic action potentials was proposed to underlie at least part of the potentiation (Shu et al., 2006). In the calyx of Held, where direct depolarization of the presynaptic terminal increases transmitter release, the effect was attributed both to an increase in the basal $\mathrm{Ca}^{2+}$ concentration (Awatramani et al., 2005) and to changes in $\mathrm{Ca}^{2+}$ entry resulting from an alteration of the action potential waveform (Hori and Takahashi, 2009). However, no change in axonal $\mathrm{Ca}^{2+}$ has been found during analog signaling in hippocampal mossy fibers (Scott et al., 2008). In view of these apparent discrepancies, it has been suggested that two forms of analog signaling occur in different preparations with various $\mathrm{ki}$ netic properties and dependences on $\mathrm{Ca}^{2+}$ (Scott et al., 2008).

To further analyze the role of $\mathrm{Ca}^{2+}$ in analog signaling, it seems advantageous to choose a preparation that allows simultaneous measurements of transmitter release and of local $\mathrm{Ca}^{2+}$ 
signaling associated in the same cell. We selected for this purpose molecular layer interneurons of the cerebellum (MLIs) (stellate and basket cells) because these cells display well characterized action potential-induced $\mathrm{Ca}^{2+}$ signals in presynaptic varicosities (Llano et al., 1997; Forti et al., 2000) and because their release properties can be assessed simultaneously with $\mathrm{Ca}^{2+}$ measurements by performing either paired synaptic recordings (Kondo and Marty, 1998) or autoreceptor current measurements (Pouzat and Marty, 1999). We find that both postsynaptic current and autoreceptor current amplitudes are strongly enhanced by somatic depolarization and that this potentiation is driven by presynaptic $\mathrm{Ca}^{2+}$ entry and subsequent protein kinase $\mathrm{C}$ (PKC) activation.

\section{Materials and Methods}

Slice preparation. Sprague Dawley rats aged 11-15 d (of either sex) were used to prepare cerebellar slices following institutional guidelines. After decapitation under deep anesthesia with isoflurane, the cerebellar vermis was quickly removed and placed into an ice-cold $\left(4^{\circ} \mathrm{C}\right)$ artificial CSF (ACSF). Parasagittal $200 \mu \mathrm{m}$ slices were cut using a vibroslicer (VT 1000S or VT 1200S; Leica Microsystems) and then placed in an incubating chamber at $34^{\circ} \mathrm{C}$ for $45-60 \mathrm{~min}$ to recover from the slicing damage. Thereafter, slices were held at room temperature before being transferred to the recording chamber. Slices were used during a $7 \mathrm{~h}$ period after decapitation.

The ACSF used for the slicing procedure and the electrophysiological recordings was composed of the following (in $\mathrm{mm}$ ): $130 \mathrm{NaCl}, 2.5 \mathrm{KCl}, 26$ $\mathrm{NaHCO}_{3}, 1.3 \mathrm{NaH}_{2} \mathrm{PO}_{4}, 10$ glucose, $2 \mathrm{CaCl}_{2}$, and $1 \mathrm{MgCl}_{2}$; osmolarity, $300 \mathrm{mOsm} / \mathrm{kg} \mathrm{H}_{2} \mathrm{O}$; $\mathrm{pH}$ set to 7.4 by the continuous bubbling of a mixture of $95 \% \mathrm{O}_{2}$ and $5 \% \mathrm{CO}_{2}$.

Electrophysiological recordings. The slice was put in the recording chamber and continuously perfused at a rate of $1-2 \mathrm{ml} / \mathrm{min}$ with ACSF. A $63 \times, 0.9$ numerical aperture water-immersion objective placed on an upright microscope (Axioskop; Zeiss) was used to identify the neurons. Cerebellar MLIs were recorded using the whole-cell configuration of the patch-clamp technique with a double EPC-9 or EPC-10 operational amplifier (HEKA Electronik). Within the molecular layer, interneurons (either stellate or basket cells) were selected following morphological criteria (including soma diameters exceeding $6 \mu \mathrm{m}$ ), as well as electrophysiological criteria (presence of largeamplitude voltage-dependent $\mathrm{Na}^{+}$currrents and of spontaneous synaptic currents in whole-cell recording).

Borosilicate glass pipettes were pulled using a two-stage vertical puller (L/M-3P-A; List Medical) and filled with an intracellular solution (IS) of the following composition (in mM): $145 \mathrm{KCl}, 10 \mathrm{GABA}, 0.05$ EGTA, 10 HEPES, $0.1 \mathrm{CaCl}_{2}$, $4.6 \mathrm{MgCl}_{2}$, $4 \mathrm{Na}_{2} \mathrm{ATP}, 0.4 \mathrm{NaGTP}, \mathrm{pH} 7.3$ with $1 \mathrm{~N}$ $\mathrm{KOH}$ and an osmolarity of $300 \mathrm{mOsm} / \mathrm{kg} \mathrm{H}_{2} \mathrm{O}$. For washout experiments, GABA was replaced by $5 \mathrm{~mm} \mathrm{KCl}$. In some experiments, the EGTA concentration was increased to 1,10 , or $30 \mathrm{~mm}$ while adjusting the $\mathrm{KCl}$ concentration to retain iso-osmolarity (see Results). Pipette resistances were usually between 5 and $7 \mathrm{M} \Omega$. The holding potential was set at -60 $\mathrm{mV}$. Series resistance $\left(R_{\mathrm{s}}\right)$ as well as membrane capacitance and input resistance were continuously monitored by measuring the current transient elicited by $-10 \mathrm{mV}$ hyperpolarizing pulses; $R_{\mathrm{s}}$ was compensated to $50 \%$ with the $R_{\mathrm{s}}$ electronic circuit of the amplifier. Typical uncompensated $R_{\mathrm{s}}$ values were $15 \mathrm{M} \Omega$, and recordings were rejected if $R_{\mathrm{s}}$ increased above $30 \mathrm{M} \Omega$.

Recordings were acquired using the Pulse software (HEKA) at a sampling rate of $5 \mathrm{kHz}$ and filtered at $1 \mathrm{kHz}$ with a Bessel filter.

Most of the recordings were done at room temperature. However, a series of experiments were performed at near-physiological temperature $\left(34-35^{\circ} \mathrm{C}\right)$ and showed that the extent of analog signaling was similar at that temperature and at room temperature (see Fig. $2 A d$ ).

Calcium imaging. For $\mathrm{Ca}^{2+}$ imaging experiments, $100 \mu \mathrm{M}$ Oregon Green BAPTA-1 (OGB-1) (Invitrogen) was added to the IS described above in replacement of $50 \mu \mathrm{M}$ EGTA. The axonal compartment of the recorded cell was visualized after letting the dye diffuse for at least $10 \mathrm{~min}$ after break-in. In some experiments, $40 \mu \mathrm{M}$ Alexa 488 (Invitrogen) was added to the IS to facilitate axon identification. In these conditions, the axon could be readily identified $<5$ min after break-in and the $\mathrm{Ca}^{2+}$ rise could be recorded on top of the Alexa 488 signal. Because of the insensitivity of the Alexa signal to $\mathrm{Ca}^{2+}$, relative fluorescence changes are smaller in experiments in which Alexa was included (see Figs. 5, 7) than in those in which Alexa was omitted (see Figs. 4, 8). The IS used for each experiment is indicated in the figure legends.

Two different setups were used for $\mathrm{Ca}^{2+}$ imaging experiments, either a homemade two-photon laser-scanning system [Collin at al. (2005) and references therein] or a single-photon system. The two-photon setup was used to first assess the axonal $\mathrm{Ca}^{2+}$ rise induced by somatic depolarizations. Once the phenomenon was well characterized with this setup, we repeated the experiments with the single-photon setup, in which we obtained the same results. The rest of the experiments, including all results presented in the figures, were performed in the latter setup.

In the single-photon setup, epifluorescence illumination used a blue light-emitting diode (470/30 $\mathrm{nm}$ excitation) controlled with an OptoLED light source (Cairn Research). A dichroic 495/low-pass filter was used to deflect the excitation light to the slice. Emitted light was collected (525/50 nm filter) with an electron multiplying CCD camera (Andor Ixon). Image series were acquired with Andor software at a frame rate of $10-20 \mathrm{~Hz}$. Such series were repeated with intervals of $2 \mathrm{~min}$, and results were averaged across trials. To check for possible saturation of the fluorescence signals, trains of 60 action potentials were routinely given at the end of the experiment to obtain an estimate of the maximal $\mathrm{Ca}^{2+}$ dependent fluorescence. Recorded signals did not exceed one-quarter of the maximum signal, indicating that the data were little affected by dye saturation.

Data analysis. Both electrophysiological data and calcium imaging data were analyzed with IGOR Pro (Wavemetrics).

Autoreceptor currents and postsynaptic currents were averaged and analyzed by measuring peak amplitude and current area (charge in picocoulombs).

$\mathrm{Ca}^{2+}$-imaging analysis was performed using a routine written in the laboratory by Brandon M. Stell. Usually, two to four regions of interest (ROIs) were chosen in the axon. Four background ROIs were taken in various areas lacking recognizable structures, and the corresponding average fluorescence was subtracted from that of the axonal ROIs. The fluorescence signals were analyzed as changes in background subtracted fluorescence with respect to prestimulus values $\left(\Delta F / F_{0}\right)$. In experiments in which OGB-1 was the only fluorescent probe in the IS, $\Delta F / F_{0}$ gives an estimate of the change of the $\mathrm{Ca}^{2+}$ concentration with respect to the basal value. When Alexa was used in addition of OGB- $1, \Delta F / F_{0}$ could not be directly interpreted as a percentage change in the $\mathrm{Ca}^{2+}$ concentration. Nevertheless, the corresponding experiments could be used to compare changes in the $\mathrm{Ca}^{2+}$ signals in test versus control conditions.

For the analysis of the kinetics of the axonal $\mathrm{Ca}^{2+}$ signal, exponential functions were fitted to rising and decaying phases of the responses (usually averages of several trials).

Statistical results are given as means $\pm \mathrm{SEM} ; n$ is the number of independent experiments, and $p$ indicates the result of Student's $t$ test comparisons. Differences were considered significant at $p<0.05$.

Drugs. All drugs were bath applied. At the beginning of drug application, perfusion was accelerated approximately fivefold for $30 \mathrm{~s}$ to fully exchange the bath with the new solution. The perfusion speed was then returned to normal values to allow diffusion of the drug into the slice tissue.

It has been reported that MLIs have a high density of $I_{\mathrm{h}}$ channels in the axon (Southan et al., 2000). To avoid any contribution of the $I_{\mathrm{h}}$ conductance to the phenomenon that will be described in this work, all the experiments aimed at characterizing the voltage dependence of the autoreceptor currents and synaptic currents (see Figs. 1-4) were done in the presence of $10 \mu \mathrm{M}$ 4-ethylphenylamino-1,2-dimethyl-6-methylaminopyrimidinium chloride (ZD 7288). Subsequent experiments performed without ZD 7288 revealed a somewhat weaker voltage dependence (compare the control plots of Figs. 6 and 8, without ZD 7288, and those of Fig. 2, with ZD 7288), but the difference did not reach statistical significance. Therefore, in the 
second part of the work examining $\mathrm{Ca}^{2+}$ signaling, all experiments were done without the drug.

To assess the actions of the PKC blocker 3-[3-[2,5-dihydro-4-(1-methyl$1 H$-indol-3-yl)-2,5-dioxo-1 $H$-pyrrol-3-yl]- $1 H$-indol-1-yl $]$ propyl carbamimidothioic acid ester mesylate (Ro 31-8220) (3 $\mu \mathrm{M})$ the slices were incubated in the drug for $1 \mathrm{~h}$ before being transferred to the recording chamber, where the drug was also included. Control experiments were done in slices incubated for $1 \mathrm{~h}$ in Ro 31-8220 free ACSF. When using $\omega$-agatoxinIVA, cytochrome $c(0.1 \mathrm{mg} / \mathrm{ml})$ was added to the ACSF to prevent nonspecific binding of the toxin (Forti et al., 2000). To minimize usage of both $\omega$-agatoxin-IVA and Ro 31-8220, the drugs were dissolved in a $10 \mathrm{ml}$ volume of ACSF and recirculated.

Drugs were purchased from Sigma-Aldrich, Tocris Bioscience, and Ascent Scientific.

\section{Results}

Autoreceptor currents as a neurotransmitter release assay It has been shown previously that a short depolarization applied to the soma of MLIs elicits a GABAergic current that is generated by released GABA binding back to axonal $\mathrm{GABA}_{\mathrm{A}}$ receptors [autoreceptor current (Pouzat and Marty, 1999)]. Autoreceptor currents can be recorded in the soma under voltage clamp because the axon cable provides an efficient electrical link between the axonal and somatic compartments (Pouzat and Marty, 1999; Mejia-Gervacio et al., 2007; Trigo et al., 2010). Reciprocally, the same electrical link ensures that somatic depolarization is mostly transmitted to the axon terminals, as the estimated cable length constant is approximately twice the physical length of the axon (Mejia-Gervacio et al., 2007; Christie and Jahr, 2008; Trigo et al., 2010). In agreement with these estimates, it has been shown in synaptically connected paired recordings that, after washing in tetrodotoxin, presynaptic somatic depolarization increases the rate of miniature synaptic currents measured in the postsynaptic cell (Glitsch and Marty, 1999).

Based on these earlier data, monitoring the amplitude of the autoreceptor current as a function of holding potential appears as an attractive method to probe possible effects of somatic depolarization on axonal exocytosis. To perform such experiments, however, cells must exhibit a stable autoreceptor current. In whole-cell recording, neurotransmitter release runs down with time, leading to a rapid decline of autoreceptor current amplitudes (Pouzat and Marty, 1999; Trigo et al., 2010). One possible mechanism for rundown is that the cytosolic GABA concentration collapses because of pipette dialysis, leading to the emptying of synaptic vesicles (Smith and Jahr, 2002). Therefore, we compared the rundown times in experiments in which the pipette solution was complemented with $10 \mathrm{~mm}$ GABA, and in control experiments in which GABA was omitted. The results show that rundown was statistically not significant up to $25 \mathrm{~min}$ of wholecell recording with a GABA-containing pipette solution, whereas it had already reduced the autoreceptor current amplitude by one-half in $10 \mathrm{~min}$ in control recordings (Fig. 1). In GABA conditions, there was an early and variable increase in autoreceptor current amplitude, leading to a peak near $10 \mathrm{~min}$ of whole-cell recording (Fig. 1C, open symbols). This increase reflects the rise of the autoreceptor currents as $\mathrm{Cl}^{-}$diffuse into the axon (Pouzat and Marty, 1999). A similar increase occurs in control conditions, but its peak occurs at shorter times (in the first minutes of recording) because it is curtailed by rundown, and it is not apparent with the sample interval used in the plot of Figure 1. Overall, the results indicate that vesicle filling accounts for a large part of rundown. In practical terms, they show that the addition of GABA eliminates much of the rundown over a period of $30 \mathrm{~min}$,
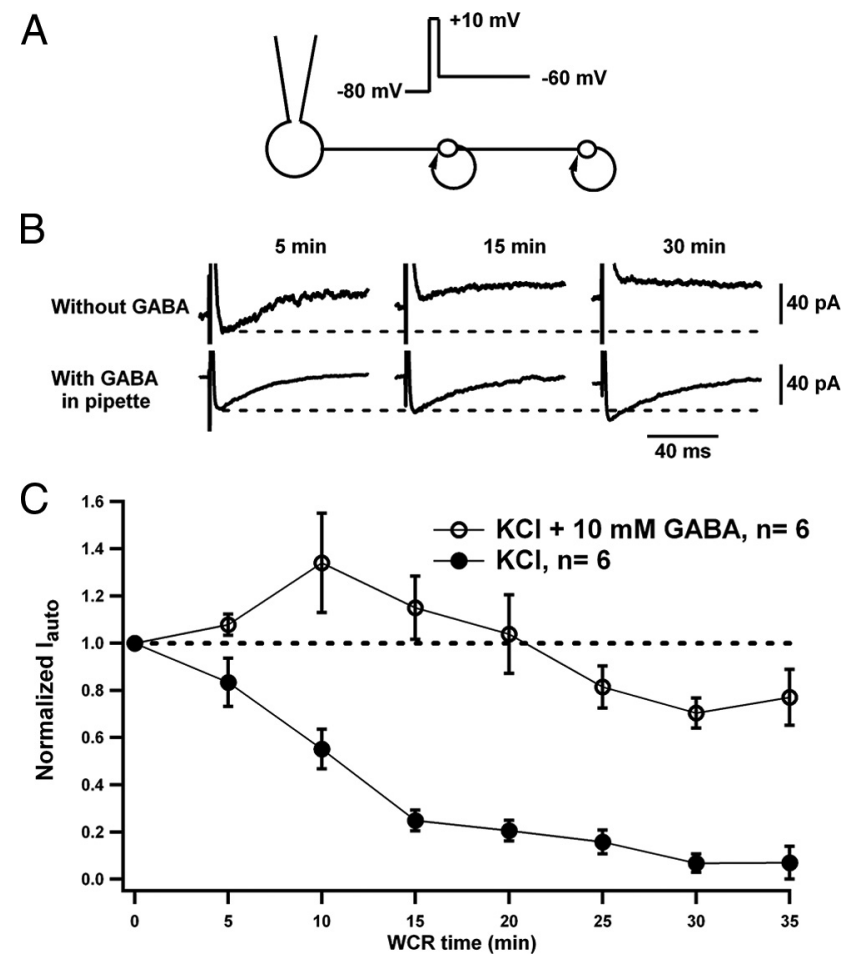

Figure 1. Autoreceptor current rundown can be slowed down by addition of intracellular GABA. $\boldsymbol{A}$, Experimental design of autoreceptor current measurements. The cell and axon are filled with a high $\mathrm{Cl}^{-}$solution. After a short depolarizing pulse to $+10 \mathrm{mV}$, the autoreceptor current is measured under voltage clamp at $-60 \mathrm{mV}$. B, Autoreceptor current measured in two cells at 5, 15, and 30 min after break-in. The cell shown in the top sequence was dialyzed with an intracellular solution lacking GABA, whereas that in the bottom sequence was dialyzed with an intracellular solution containing $10 \mathrm{~mm}$ GABA. Note the more rapid autoreceptor current amplitude decrease in the top sequence than in the bottom sequence. $C$, Summary results for experiments as in $\boldsymbol{B}$. Autoreceptor currents were measured as a function of time in whole-cell recording either with (open symbols) or without (closed symbols) $10 \mathrm{~mm}$ GABA in the pipette solution. Data (mean $\pm \mathrm{SEM} ; n=6$ cells) are normalized to the amplitude registered during the first minute of whole-cell recording.

thus opening the way to a quantitative examination of autoreceptor currents as a function of potential.

\section{Effects of previous holding potential on autoreceptor current amplitude}

To assay the effects of somatic potential on the autoreceptor current amplitude, we adopted the protocol illustrated in Figure $2 \mathrm{Aa}$. The pipette solution was filled with a GABA-containing $\mathrm{KCl}$ solution. Experiments were performed under voltage clamp, and the somatic potential was held for periods of $10 \mathrm{~s}$ each at various values ranging from -80 to $-50 \mathrm{mV}$. To eliminate any bias linked to rundown, the order of the various holding potential periods was randomized. Short voltage pulses (1 ms long; test potential, $10 \mathrm{mV}$ ) were applied at the end of the $10 \mathrm{~s}$ periods to elicit an action potential in the axon. At the end of the pulse, the somatic potential was reset to $-60 \mathrm{mV}$ to measure the autoreceptor current. As can be seen in Figure $2 A b$, selecting a more depolarized value for the prepulse potential increased the charge carried by the autoreceptor current. This effect was gradual in the range comprised between -80 and $-50 \mathrm{mV}$ (Fig. $2 A c$ ). It was stable with time in the whole-cell recording mode (Fig. $2 B$ ). Finally, it had similar amplitudes at room temperature and at physiological temperature (Fig. $2 A d$ ). These results suggest that the release of GABA from MLI axons is enhanced by subthreshold somatic depolarization. 
A

a

C

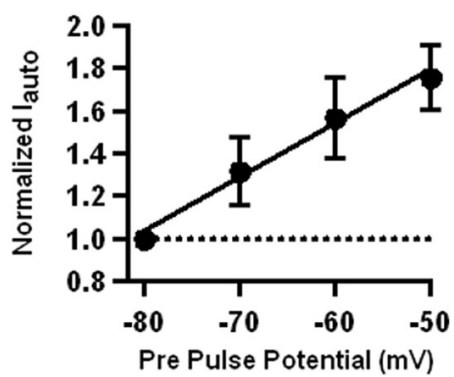

b

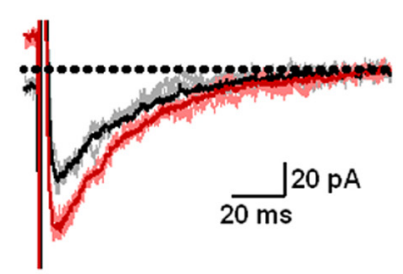

d

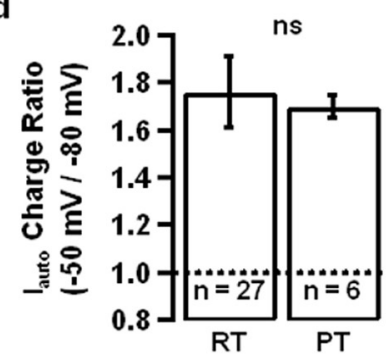

B

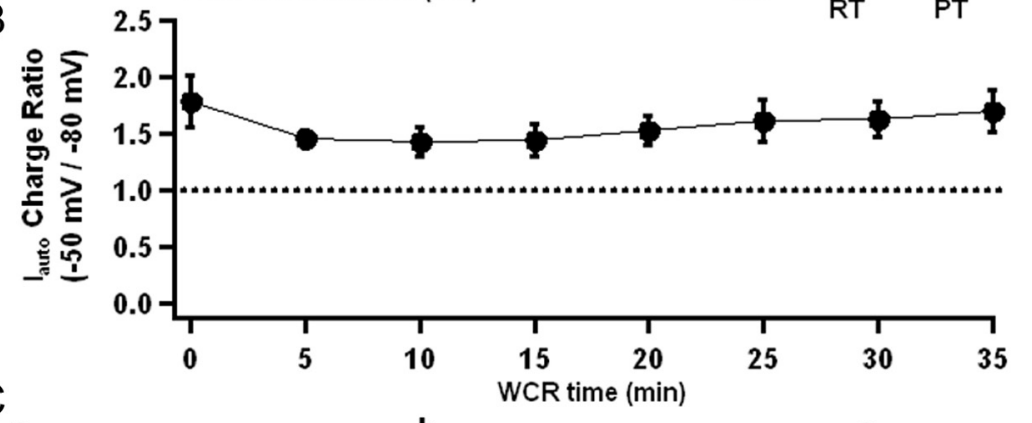

a
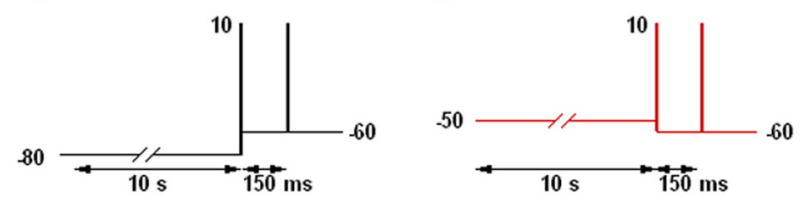

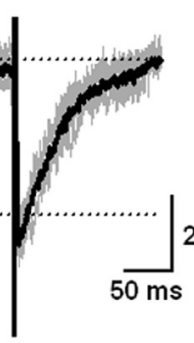

$25 \mathrm{pA}$

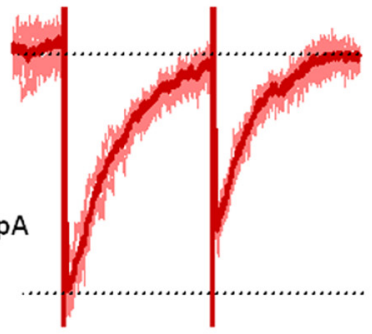

Figure 2. Autoreceptor current as a function of prepulse potential. $A$, Selecting a depolarized prepulse potential increases the autoreceptor current. $\boldsymbol{A a}$, Schematic of the experimental design. $\boldsymbol{A} \boldsymbol{b}$, Examples of individual traces (in gray and pink) and average traces (black and red; averages of 6 individual traces) for prepulse potential values of $-80 \mathrm{mV}$ (gray and black) and $-50 \mathrm{mV}$ (pink and red). Ac, Normalized variation of the autoreceptor current integral as a function of prepulse potential (means \pm SEM from 27 experiments) can be fitted with a straight line (black). Ad, Summary data comparing the autoreceptor current integral ratio (for prepulse potentials of -80 and $-50 \mathrm{mV}$ ) at room temperature and at near-physiological temperature. $\boldsymbol{B}$, Plot of the normalized response $(-50 \mathrm{mV} /-80 \mathrm{mV}$ ratio $)$ as a function of time in whole-cell recording, demonstrating the stability of this parameter in whole-cell recording conditions. Means \pm SEM from six experiments are shown. (Several symbols are larger than the corresponding error bars.) $C$, Alteration of the paired-pulse ratio as a function of prepulse potential. $\mathbf{C a}, \boldsymbol{C b}$, Modification of the experimental protocol to examine the effect of prepulse potential on the paired-pulse ratio. Note that, in the example shown, the paired-pulse ratio is $>1$ for a prepulse potential of $-80 \mathrm{mV}$ ( $\mathbf{C a}$ ) (average of 6 traces) and is $<1$ for a prepulse potential of $-50 \mathrm{mV}$ (Cb) (average of 6 traces). Cc, Summary data for 17 experiments as in $\mathbf{C a}$ and $\boldsymbol{C b}$.

However, an alternative interpretation could be that somatic depolarization changes the state of the axonal receptors such that they become more sensitive to GABA, in which case the results would not require a modification of GABA release. If the probability of release is modified, then the paired-pulse ratio is expected to change. We therefore modified the protocol as c

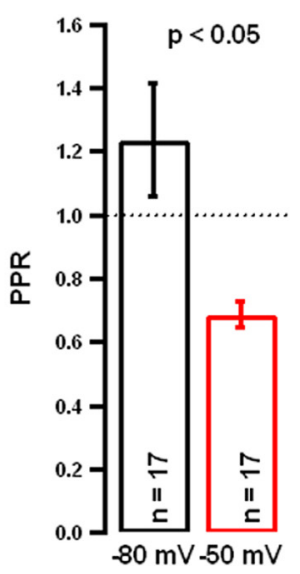

illustrated in Figure $2 C$ to include a second pulse applied with a $150 \mathrm{~ms}$ interval at $-60 \mathrm{mV}$. [A comparatively long interval was chosen because autoreceptor currents would otherwise overlap, raising concerns on the effect of changes in the axonal space clamp on the transfer function of the second measurement (Pouzat and Marty, 1999).] It was then found that the paired-pulse ratio was significantly decreased by changing the prepulse from -80 to $-50 \mathrm{mV}$ (Fig. 2C). This is consistent with the hypothesis that GABA release is enhanced by depolarization.

\section{Effect of presynaptic holding potential} in paired recordings

To test whether somatic depolarization also affects synaptic currents, we performed paired recordings between synaptically connected MLIs (Kondo and Marty, 1998). As before, the presynaptic pipette solution contained GABA to maintain rundown at a minimum. The presynaptic potential was held for at least $10 \mathrm{~s}$ either at $-80 \mathrm{mV}$ or at $-50 \mathrm{mV}$, and pairs of voltage steps to $+10 \mathrm{mV}(30-50$ $\mathrm{ms}$ interpulse interval) were applied presynaptically, while maintaining the postsynaptic potential at $-60 \mathrm{mV}$ (Fig. $3 A$ ). Unlike autoreceptor currents, synaptic currents fluctuated widely from trial to trial, as reported previously (Fig. $3 B$ ) (Kondo and Marty, 1998; Pouzat and Marty, 1999). Because synaptic currents can be either excitatory or inhibitory under physiological conditions (Chavas and Marty, 2003), the standard acronym "IPSC" would be misleading, and we call them "GABAergic postsynaptic currents" hereafter (abbreviated GPSCs). Averaging revealed a significant increase of the GPSC amplitude when depolarizing the holding potential (from $397 \pm 59 \mathrm{pA}$ at $-80 \mathrm{mV}$ to $563 \pm 38 \mathrm{pA}$ at $-50 \mathrm{mV}$ in the example shown; $p<0.05$ ) (Fig. 3B). Likewise, a group data analysis performed on mean amplitudes across experiments revealed a large and statistically significant amplitude increase (Fig. 3C, left panel). Two additional sets of results indicated that the release probability was enhanced by presynaptic depolarization. First, the pairedpulse ratio (measured as the ratio between the peak amplitude of the second GPSC and that of the first) was decreased, indicating that the change was taking place presynaptically (Fig. 3C, middle panel). Second, the failure rate was reduced, again in agreement with a presynaptic locus (Fig. $3 C$, right panel). Together, the results indicate that subthreshold somatic depolarization increases the amplitudes both of postsynaptic currents and of autoreceptor currents, reflecting an increased release probability of GABA. Quantitatively, the extent of 
the voltage dependence appears similar, with an enhancement of autoreceptor current charge by 1.76 -fold between -80 and $-50 \mathrm{mV}$, and a corresponding enhancement of synaptic current amplitude by 1.48 -fold.

\section{Association of axonal calcium increase with depolarization-induced GABA release}

Various mechanisms have been proposed to account for depolarizationinduced enhancement of transmitter release. At the calyx of Held, the basal $\mathrm{Ca}^{2+}$ concentration increases in the presynaptic terminals in response to subthreshold depolarization, reflecting the partial activation of voltage-dependent $\mathrm{Ca}^{2+}$ channels, and this change in basal $\mathrm{Ca}^{2+}$ is proposed to be responsible for the increase in release probability (Awatramani et al., 2005). A similar mechanism applies to cortical neurons ( $\mathrm{Yu}$ et al., 2010). In hippocampal mossy fiber terminals, however, neither the basal $\mathrm{Ca}^{2+}$ concentration nor the spike-evoked axonal $\mathrm{Ca}^{2+}$ transients were found to change on somatic depolarization (Scott et al., 2008). Thus, the mechanisms of analog signaling may differ among preparations.

To study the effects of somatic depolarization on the axonal $\mathrm{Ca}^{2+}$ concentration, we performed a new series of experiments while including the highaffinity $\mathrm{Ca}^{2+}$-sensitive dye OGB- 1 in the recording solution, and we imaged the recorded neuron either with a homemade two-photon microscope or with an imaging system based on a fast and sensitive CCD camera (see Materials and Methods). Dendrites were filled with dye within a few minutes. They were readily recognizable as they were straight and short, radiating from the soma. The axon extended over a much longer distance (Fig. 4A) and filled more slowly. Useful axonal measurements could start $\sim 20$ min after establishment of whole-cell recording. As before, voltage steps of various amplitudes and durations were applied to the soma under voltage clamp to measure the autoreceptor current as a function of the previous somatic potential. In agreement with previous studies (Glitsch et al., 1999; Christie and Jahr, 2008), we found that changes in the somatic potential influenced the basal $\mathrm{Ca}^{2+}$ concentration in axonal sites. Measurements with two-photon imaging indicated that this amounted to a $1.52 \pm 0.11$-fold change for $20 \mathrm{mV}(n=3 ;-70$ to $-50 \mathrm{mV}$ steps), and measurements with the CCD camera indicated a $1.31 \pm 0.12$-fold change for $20 \mathrm{mV}(n=4 ;-60$ to -40 $\mathrm{mV}$ steps; all data taken at a distance of $\sim 50 \mu \mathrm{m}$ from the soma).

The amplitude of the axonal response decreased as a function of distance from the soma (Fig. $4 A$ ). In the example shown, the data could be fitted with an exponential yielding a length constant of $71 \mu \mathrm{m}$ (Fig. $4 \mathrm{Ba}$ ). The average length constant was $92 \pm 26 \mu \mathrm{m}$
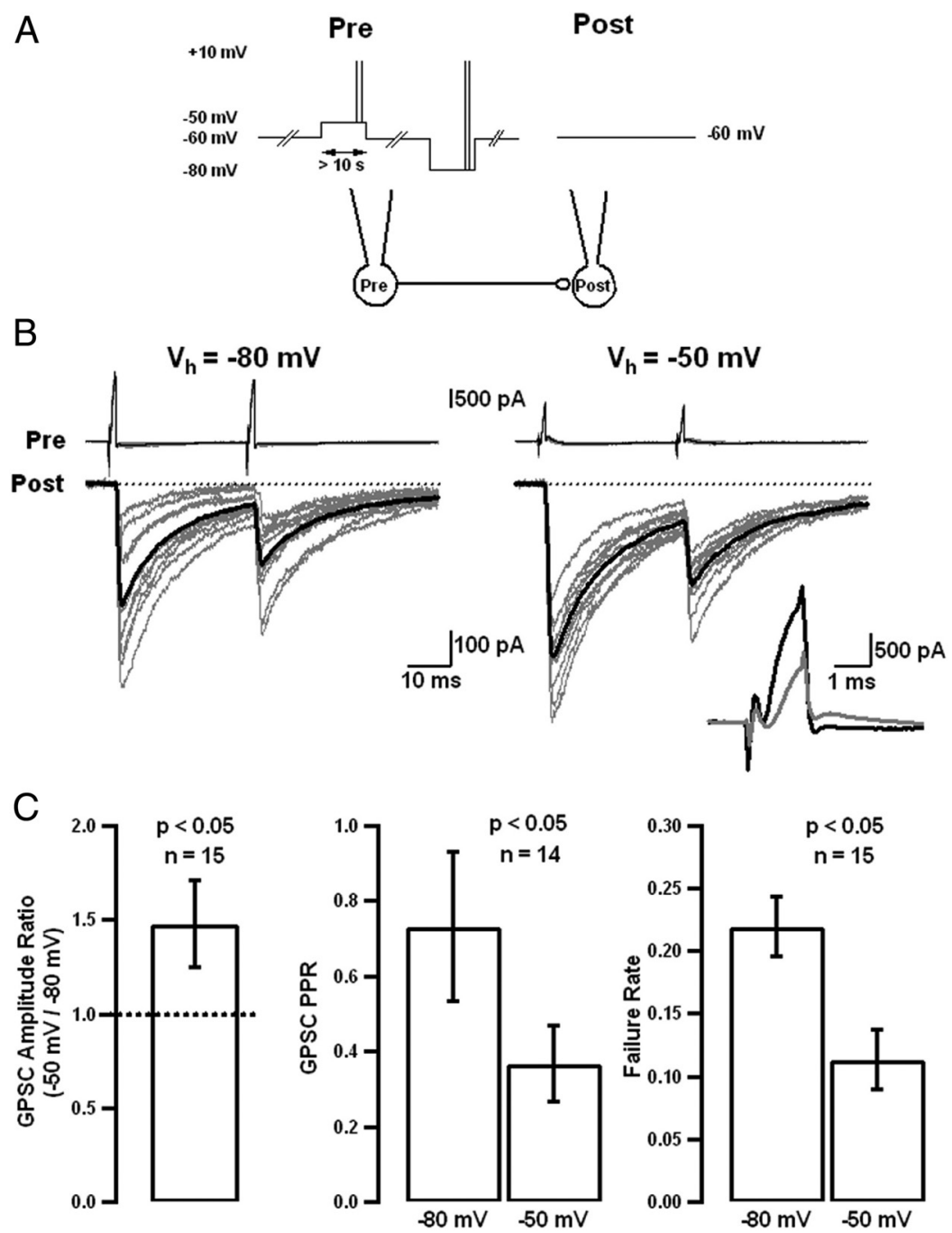

Figure 3. Presynaptic depolarization increases postsynaptic current in paired recordings. $\boldsymbol{A}$, Paired recordings of synaptically connected MLIs were alternatively submitted to the two illustrated voltage protocols. In one protocol, the presynaptic MLI was held to $-50 \mathrm{mV}$. In both protocols, the postsynaptic cell was held at $-60 \mathrm{mV}$. B. Presynaptic and postsynaptic traces obtained from one paired recording. Both single sweep data (gray traces) and average data (black traces) are shown. On the postsynaptic side, there the paired-pulse ratio is decreased. Inset, Superimposed traces of presynaptic voltage-dependent currents show a decreased

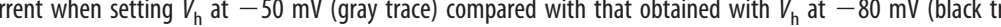
$-50 \mathrm{mV}$ ratio; center, paired-pulse ratio; right, failure rate). Statistical tests: one-sample $t$ test versus 1 (left); paired $t$ test (center and right). Error bars indicate SEM.

( $n=4$; data for -60 to $-40 \mathrm{mV}$ somatic depolarization). In view of previous results in other preparations as well as in MLIs, the simplest explanation for this decrement involves voltagedependent $\mathrm{Ca}^{2+}$ entry after the passive spread of depolarization along the axon cable. The alternative view that the source of the $\mathrm{Ca}^{2+}$ was in the soma, and that the $\mathrm{Ca}^{2+}$ was flowing into the axon by diffusion, is highly unlikely for two reasons. First, as reported previously for action potential-driven signals (Llano et al., 1997), the maximum $\mathrm{Ca}^{2+}$ increase was smaller in the soma than in the proximal axon (see example in Fig. $4 \mathrm{Ba}$ ). Second, in response to a step depolarization of the soma, the axonal concentration followed an exponential function of time with a time constant (1.1 s in the example shown) that did not display any significant relationship to the distance from the soma (Fig. $4 B b$ ). By contrast, a diffusion process would display a sigmoid time 


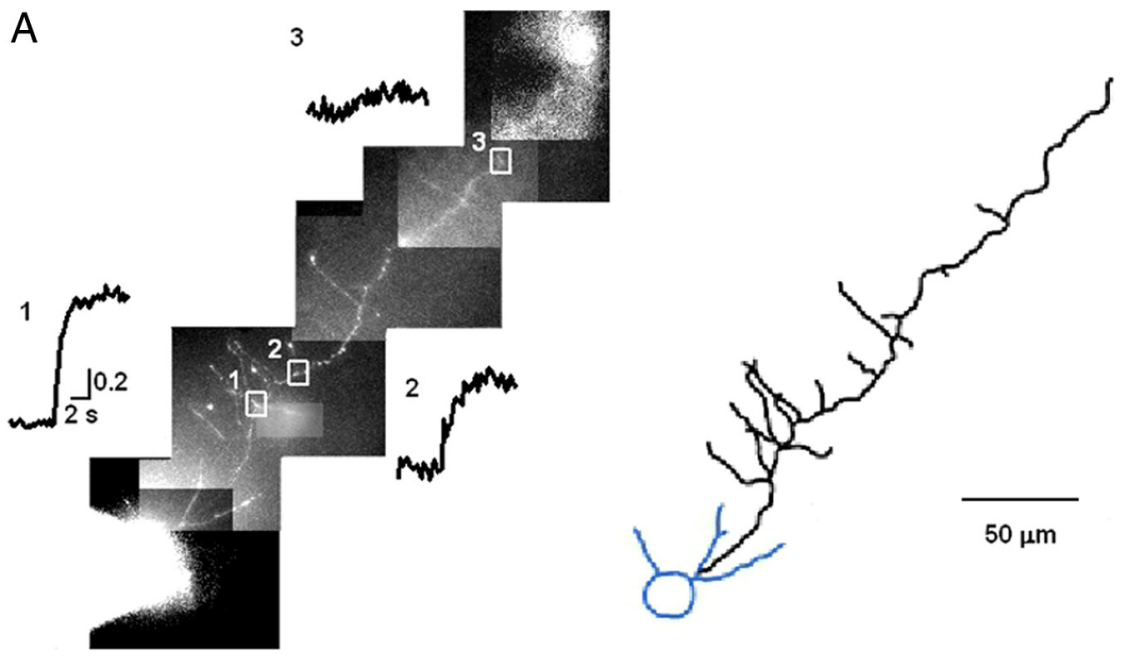

B a

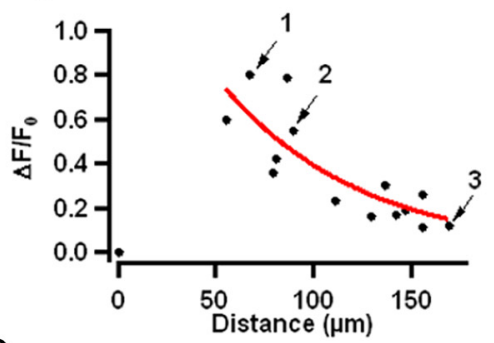

C

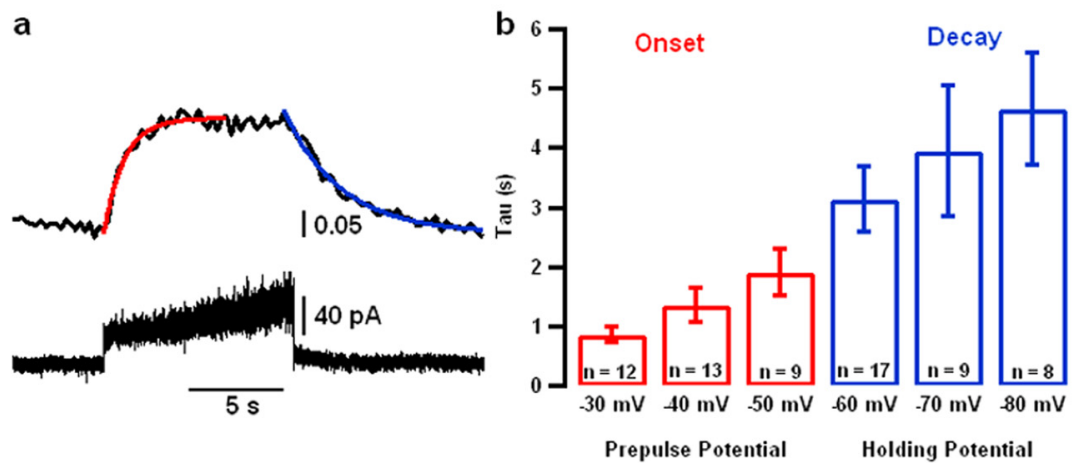

Figure 4. Axonal $\mathrm{Ca}^{2+}$ concentration changes in response to somatic depolarization. $A$, Left, Axonal $\mathrm{Ca}^{2+}$ concentration changes in three different axonal sites of a stellate cell in response to a step somatic depolarization from -60 to $-40 \mathrm{mV}$. Note the gradual attenuation of the axonal response as a function of distance from the soma. Right, Morphological reconstruction of the somatodendritic (blue) and axonal (black) domains of the cell. Ba, Amplitude of the relative axonal $\mathrm{Ca}^{2+}$ concentration changes as a function of distance from the soma. The point at 0 distance corresponds to somatic measurements, which had a very weak response $\left(\Delta F / F_{0}\right.$ of 0.0016$)$. Axonal data have not been analyzed for points close to the soma because of the contamination of the fluorescence signal by somatic signal (flare). The amplitude versus distance relationship has been fitted with an exponential having a length constant of $71 \mu \mathrm{m}$ (red curve). $\boldsymbol{B} \boldsymbol{b}$, Onset kinetics of the $\mathrm{Ca}^{2+}$ concentration changes was approximated with monoexponential curves. The time constant of these curves was close to $1 \mathrm{~s}$ and was independent of the location along the axon. Numbers $1-3$ indicate ROls identified in $\boldsymbol{A}$. The red line is a linear fit to the data points. $\mathbf{C} \boldsymbol{a}$, Example of on and off relaxations in response to a depolarizing step from $-60 \mathrm{to}-40 \mathrm{mV}$. Red and blue lines, Exponential fits to the data (time constants: $-40 \mathrm{mV}, 1.08 \mathrm{~s} ;-60$ $\mathrm{mV}, 2.98 \mathrm{~s}$ ). ( $(\boldsymbol{b}$, Average time constants of such relaxations (data collected in the presence of tetrodotoxin). The IS used for the experiments shown in this figure did not contain Alexa (see Materials and Methods). Error bars indicate SEM.

course with a steeply increasing delay at increasing distances from the source. Therefore, the source of the depolarization-induced $\mathrm{Ca}^{2+}$ rise is axonal. Near rest, the axon length constant is approximately twice the value of the physical cable [500 and $250 \mu \mathrm{m}$, respectively (Mejia-Gervacio et al., 2007)], predicting a voltage decrement of only $39 \%$ from the soma to the tip of the axon. At more depolarized values, however, the axon length constant is likely to decrease because of the gradual activation of voltage- dependent channels of the axon membrane, and this explains that the length constant that is derived from the $\mathrm{Ca}^{2+}$ responses to somatic depolarization to -40 $\mathrm{mV}$ is shorter (92 $\mu \mathrm{m})$. Thus, for larger somatic depolarizations, analog signaling will increasingly target proximal synapses rather than distant synapses. Note that the density of axon collaterals is larger in the proximal part of the axon than in the distal part, as illustrated in Figure 4, so that many synaptic sites will remain significantly affected by the somatic influence.

At the end of a depolarizing pulse, the $\mathrm{Ca}^{2+}$ concentration returned to basal values with a time constant that was longer than that observed during the rise (Fig. $4 \mathrm{Ca}, 2.98$ and $1.08 \mathrm{~s}$ in the example shown). Likewise, time constants for $\mathrm{Ca}^{2+}$ concentration rises were shorter for larger depolarizing pulses. Average values for on and off time constants are plotted in Figure $4 \mathrm{Cb}$ as a function of membrane potential. These results indicate that the kinetics of the $\mathrm{Ca}^{2+}$ signal accelerates with somatic depolarization. They can be understood by a simple one-compartment model in which $\mathrm{Ca}^{2+}$ entry increases with depolarization, and $\mathrm{Ca}^{2+}$ exit rate is proportional to the difference between the instantaneous $\mathrm{Ca}^{2+}$ concentration and the equilibrium point for this concentration (Neher and Augustine, 1992).

Simultaneous measurements of axonal $\mathrm{Ca}^{2+}$ rise and of autoreceptor currents Like the increase in the basal $\mathrm{Ca}^{2+}$ concentration, the depolarization-induced facilitation of GABA release was not instantaneous. To compare the kinetics of the axonal $\mathrm{Ca}^{2+}$ concentration and of GABA release in the same axon, the protocol illustrated in Figure $5 A$ was developed. $\mathrm{Ca}^{2+}$ imaging was performed on a proximal section of the axon [approximate distance from the soma, $50 \mu \mathrm{m}$ (Fig. $5 A a)$. Subthreshold depolarizations (from -60 to $-40 \mathrm{mV}$ ) were applied to the soma with durations up to $10 \mathrm{~s}$, and a short suprathreshold pulse was given at the end of the depolarizing prepulse to elicit a single action potential and record the associated autoreceptor current (Fig. $5 A b, c)$. The $\mathrm{Ca}^{2+}$ concentration at the prepulse potential and the autoreceptor current amplitude measured in response to the pulse potential grew with a similar time course (Fig. $5 A b, c$ ). Average normalized data from such experiments were fitted with singleexponential functions of prepulse duration, and the time constants of the axonal $\mathrm{Ca}^{2+}$ increase and autoreceptor current data were identical within experimental error (Fig. 5B). Measurements of the time constant of the return of the release probability to its resting level after a long depolarizing prepulse gave likewise 
a slow value (at $-60 \mathrm{mV}, 2.4 \pm 1.7 \mathrm{~s} ; n=$ 6 ), which was not statistically different from the corresponding time constant of the fluorescence signal (Fig. 4Cb). These results resemble those obtained previously at the calyx of Held (Awatramani et al., 2005).

Lack of effect of somatic depolarization on action potential-induced $\mathrm{Ca}^{2+}$ transients

Depolarization of the axonal membrane may change the inactivation status of voltage-dependent channels (Geiger and Jonas, 2000) and consequently the shape of the action potential waveform (Shu et al., 2006). In addition, the depolarization and associated $\mathrm{Ca}^{2+}$ rise may alter the responsiveness of $\mathrm{Ca}^{2+}$ channels to depolarization (Hori and Takahashi, 2009). Therefore, we next investigated the effects of prepulse depolarization on action potential-induced $\mathrm{Ca}^{2+}$ transients in axonal varicosities. As can be seen in Figure $5 A b$, the peak value of action potentialinduced transients was increased by previous depolarization. This resulted in a significant increase in the $\Delta F / F_{0}$ signal when taking $F_{0}$ at the holding potential (Fig. 5Ca, left column). However, this effect was entirely attributable to the increase in basal $\mathrm{Ca}^{2+}$ induced by the depolarization. If the transients were corrected by a baseline shift offsetting the change in basal level (i.e., taking $F_{0}$ at the end of the prepulse potential), their amplitudes were found to be unaffected by the previous depolarization (Fig. $5 \mathrm{Ca}$, right column). These results indicate that the amount of $\mathrm{Ca}^{2+}$ entry that is elicited by one action potential does not depend on the prepulse potential.

Because OGB-1 is a high-affinity dye, it was reasoned that partial dye saturation could decrease the fluorescence signal associated with action potentials after a depolarizing prepulse. To quantify this effect, we compared the absolute values of the fluorescence signals associated with one, two, and four action potentials with and without prepulse. In conformity to previous data (Forti et al., 2000), the control signals displayed only a small amount of saturation, with an estimated saturation value equal to 2.7 times the signal obtained after four action potentials (Fig. $5 C b$, black symbols). Importantly, the data obtained after a depolarizing prepulse could be modeled with the same binding curve as the control data, except for a leftward shift corresponding to an increased $\mathrm{Ca}^{2+}$ level at rest. This indicates that depolarization did not alter
A a
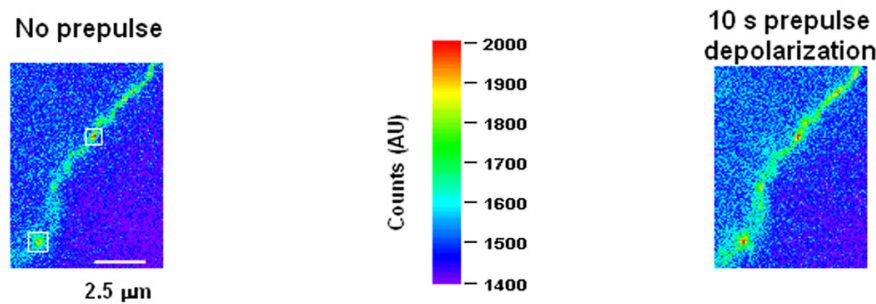

b
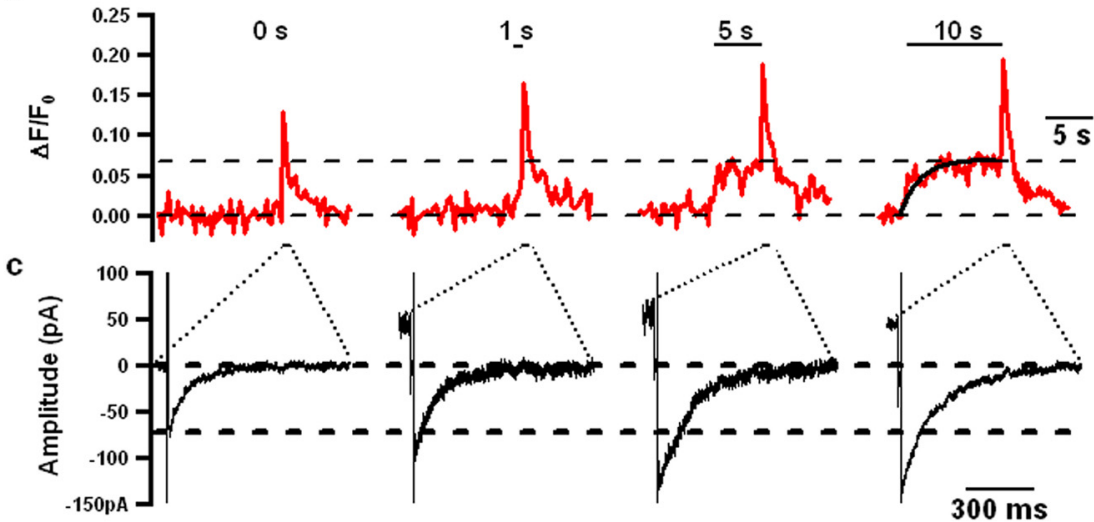

B a

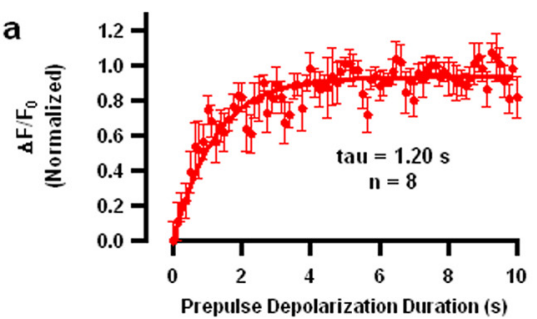

C a

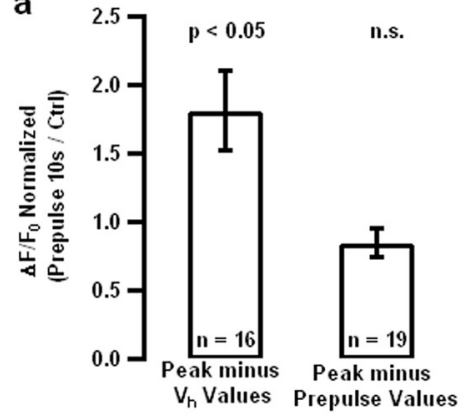

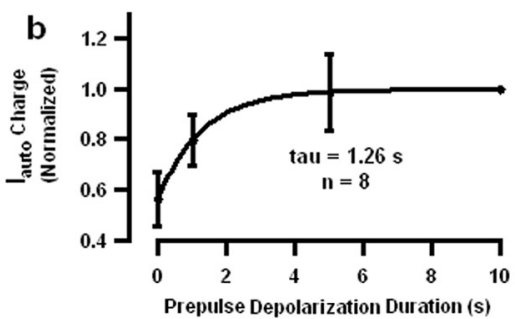

b

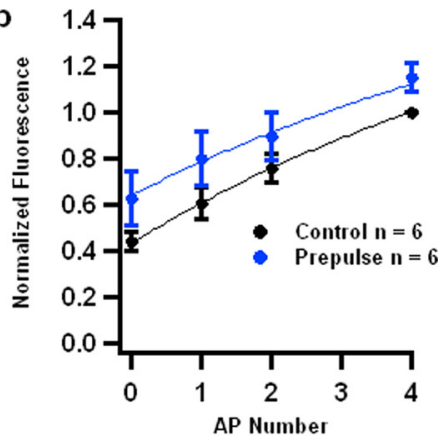

Figure 5. Simultaneous measurements of GABA release and of axonal calcium concentration during analog signaling. $\boldsymbol{A}$, Experimental protocol and data from an exemplary cell. $\mathbf{A a}$, Section of the axon showing an increase in $\mathrm{Ca}^{2+}{ }^{2}$-sensitive fluorescence on somatic depolarization (from -60 to $-40 \mathrm{mV}$ ). $\boldsymbol{A} \boldsymbol{b}$, Axonal $\mathrm{Ca}^{2+}$ signals in response to step subthreshold depolarizations (to $-40 \mathrm{mV}$ ) of increasing durations, followed by a short superthreshold step. An exponential fit to the rise of the fluorescence trace is shown for the last panel (black curve; time constant, $2.0 \mathrm{~s}$ ). Ac, Autoreceptor currents obtained in the same cell, in response to the test step. These currents increase in size as a function of the duration of the subthreshold depolarization. $\boldsymbol{B}$, The increases in axonal concentration and in autoreceptor current amplitude follow the same time course. Average normalized $\mathrm{Ca}^{2+}$ concentration and autoreceptor amplitude data from eight cells as in $\boldsymbol{A}$ have been fitted with exponentials displaying a time constant of $1.20 \mathrm{~s}(\boldsymbol{B a})$ and $1.26 \mathrm{~s}(\boldsymbol{B} \boldsymbol{b})$, respectively. $\boldsymbol{C}$, Subthreshold depolarization does not alter the amplitude of subsequent test depolarizations. $(\boldsymbol{a}$, Peak fluorescence amplitude minus holding potential value increases on insertion of a depolarizing prepulse (paired $t$ test, $p<0.05$ ), but measurements of the peak amplitude from the prepulse baseline do not reveal any significant change (paired $t$ test, $p>0.05$ ), indicating that the prepulse does not alter the amount of $\mathrm{Ca}^{2+}$ entry elicited by the test pulse. $\boldsymbol{C} \boldsymbol{b}$, Fluorescence values measured at rest $(\mathrm{AP}$ number, 0 ) and at the peak of the response to one, two, or four action potentials, both in control conditions (in black) and after a depolarizing prepulse to $-40 \mathrm{mV}$ (in blue). Here, absolute fluorescence values are shown rather than the $\Delta F / F_{0}$ quantification used elsewhere in this paper. The data have been normalized with respect to the peak response to four action potentials without prepulse. They have been fitted using a common hyperbolic function with an asymptote of 2.7 and a half-saturation value of 10 [fitting function: $y=2.7 /(1+10(x+b))$, with $b=1.9$ without prepulse and $b=3.8$ with prepulse]. The IS used for the experiments shown in this figure contained Alexa. Error bars indicate SEM. 
the amount of $\mathrm{Ca}^{2+}$ entry associated with action potentials (Fig. $5 \mathrm{Cb}$, blue points). As an additional confirmation of the same point, if the average data of Figure $5 \mathrm{Ca}$ were corrected using the saturation curve of Figure $5 \mathrm{Cb}$, they gave a corrected ratio of the calcium increase with and without prepulse very close to 1 .

Pharmacology of depolarization-induced $\mathrm{Ca}^{2+}$ rise and associated facilitation of GABA release

It was pointed out previously that the source of the elevation in axonal $\mathrm{Ca}^{2+}$ concentration during analog signaling is located in the axon. Because somatic depolarization is passively transmitted to the axon (Glitsch and Marty, 1999; Mejia-Gervacio et al., 2007), it seems likely that the depolarization-induced $\mathrm{Ca}^{2+}$ rise could be the consequence of voltage-dependent $\mathrm{Ca}^{2+}$ entry (Awatramani et al., 2005). Therefore, we tested various blockers of voltage-dependent $\mathrm{Ca}^{2+}$ channels. Cadmium (50 $\mu \mathrm{M}$; applied for $10 \mathrm{~min}$ ), a broad-spectrum blocker of these channels, reduced the axonal $\mathrm{Ca}^{2+}$ concentration increase to $31 \pm 6 \%(p<0.001 ; n=7)$ of the control value. Because voltage-dependent $\mathrm{Ca}^{2+}$ entry in MLI axons is mainly attributable to P/Q Ca ${ }^{2+}$ channels (Forti et al., 2000), we next tested the effects of the specific blocker of P/Q $\mathrm{Ca}^{2+}$ channels, $\omega$-agatoxin-IVA. This toxin inhibited the increase in the basal axonal $\mathrm{Ca}^{2+}$ concentration to $43 \pm 9 \%$ of the control value $(p<0.001 ; n=6)$ (Fig. 6). Thus, most of the voltagedependent axonal $\mathrm{Ca}^{2+}$ entry associated with analog signaling occurs through $\mathrm{P} / \mathrm{Q} \mathrm{Ca}^{2+}$ channels.

The present results indicate that a large part of the $\mathrm{Ca}^{2+}$ responsible for analog signaling is provided by $\mathrm{Ca}^{2+}$ entry after the activation of voltage-dependent $\mathrm{Ca}^{2+}$ channels. Nevertheless, $\sim 30 \%$ of the $\mathrm{Ca}^{2+}$ signal appears to be resistant to $\mathrm{Ca}^{2+}$ channel blockers. This component could represent a contribution of intracellular $\mathrm{Ca}^{2+}$ stores (Llano et al., 2000). In neurohypophyseal terminals, intracellular stores are recruited by voltage through the activation of dihydropyridine receptors (De Crescenzo et al., 2006). Therefore, we tested the sensitivity of analog signaling in MLIs to the L-type channel blocker nimodipine. We found that 10 min incubation with $20 \mu \mathrm{M}$ nimodipine did not affect the amplitude of autoreceptor currents measured at a fixed potential (peak autoreceptor current amplitude in nimodipine at $-80 \mathrm{mV}, 55.6 \pm 10.8 \mathrm{pA}$; corresponding control values, $63.2 \pm 15.6 \mathrm{pA} ; p>0.05 ; n=7)$. In addition, nimodipine failed to significantly affect the sensitivity of autoreceptor current amplitude to the prepulse potential $(-50 \mathrm{mV} /-80 \mathrm{mV}$ autoreceptor charge ratio was $1.50 \pm 0.17$ in nimodipine vs $1.67 \pm 0.16$ in control runs; $p>0.05 ; n=7$ ). These results indicate that L-type $\mathrm{Ca}^{2+}$ channels do not play a significant role in analog signaling.

We then asked whether the target of the entering $\mathrm{Ca}^{2+}$ ions was closely associated with the entry channels or whether it was, on the contrary, far from the channels. To address this question, we probed various doses of the slow $\mathrm{Ca}^{2+}$ buffer EGTA. In these experiments, GABA was included in the recording pipette, and the autoreceptor current was measured after waiting for $10 \mathrm{~min}$ to allow diffusion of EGTA in the axon. The amplitude of the autoreceptor currents was weakly dependent on the EGTA concentration. Thus, $10 \mathrm{~mm}$ EGTA failed to inhibit autoreceptors significantly (Fig. 7B), whereas $10 \mathrm{~mm}$ of the fast buffer BAPTA, which has a very similar steady-state buffering power as $10 \mathrm{mM}$ EGTA, blocks autoreceptors entirely after 10 min of recording (Pouzat and Marty, 1999). These results indicate that, at this synapse, as in another previously studied GABAergic synapse, the
A
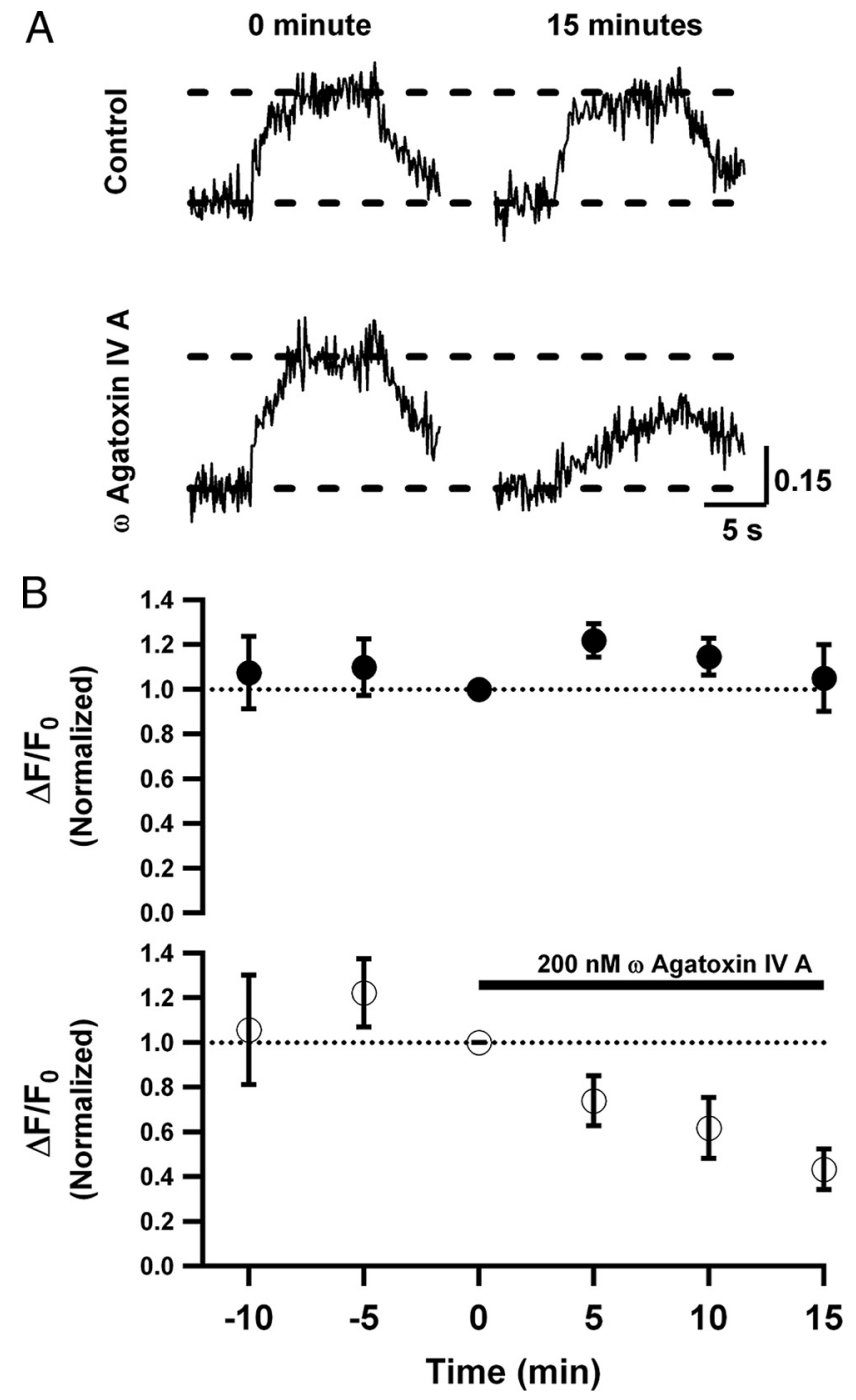

Figure 6. Sensitivity of axonal $\mathrm{Ca}^{2+}$ concentration changes to $\omega$-agatoxin-IVA. $\boldsymbol{A}$, Example recordings showing a stable $\mathrm{Ca}^{2+}$ concentration response to a step somatic depolarization (from -60 to $-40 \mathrm{mV}$; top row) and, in another cell, the inhibition of a similar response after $15 \mathrm{~min}$ of bath perfusion with the $\mathrm{P} / \mathrm{Q}$ channel blocker $\omega$-agatoxinIVA (bottom row). B, Summary plot comparing the time course of the axonal $\mathrm{Ca}^{2+}$ concentration response in control experiments, in which no change was made to the bath (closed symbols), and in test experiments, in which the toxin was added to the bath. The IS used for the experiments shown in this figure contained Alexa. Error bars indicate SEM.

$\mathrm{Ca}^{2+}$-sensitive sensor for vesicle release is closely associated to the $\mathrm{Ca}^{2+}$ channels (Fig. $7 A, B$ ) (Bucurenciu et al., 2008). In addition, we found that, when using various prepulse potentials, the autoreceptors remained sensitive to the prepulse potential up to $10 \mathrm{~mm}$ EGTA but lost their sensitivity to this potential at $30 \mathrm{~mm}$ (Fig. $7 \mathrm{~A}, C$ ). Ten millimolar EGTA almost abolished the voltage dependence of the axonal OGB-1 signal (Fig. $7 D, E$ ). These results differ strikingly from those previously reported at the calyx of Held, in which 1 mM EGTA eliminated almost completely the effects of terminal depolarization on transmitter release (Awatramani et al., 2005), as well as those obtained in hippocampal granule cells, in which infusion of $10 \mathrm{~mm}$ EGTA from the soma strongly inhibited analog signaling (Alle and Geiger, 2006). They indicate that in MLIs, the $\mathrm{Ca}^{2+}$-sensitive site responsible for analog signaling is located in the close vicinity of the $\mathrm{Ca}^{2+}$ entry site. 

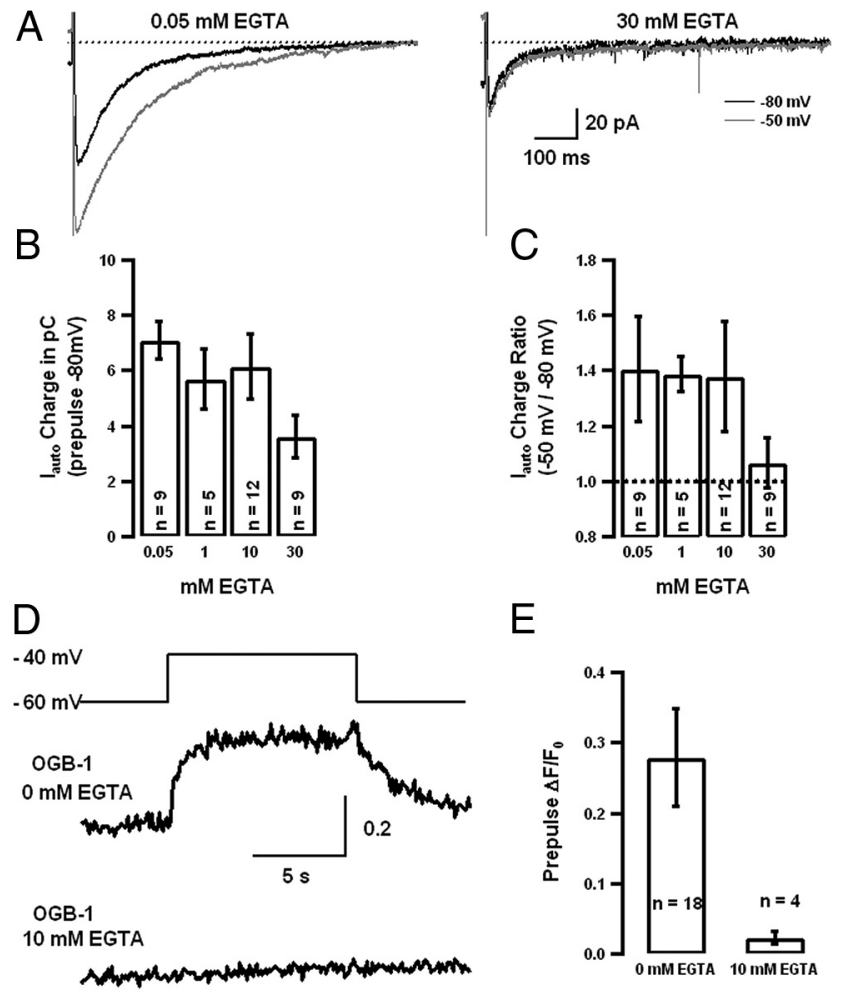

E

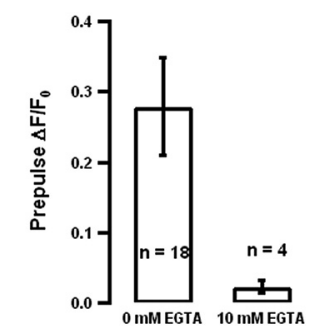

Figure 7. Sensitivity of analog signaling to intracellular $\mathrm{Ca}^{2+}$ buffers. $A$, Recordings from two experiments showing a large increase in autoreceptor current with $0.05 \mathrm{~mm}$ intracellular EGTA (left), but not with $30 \mathrm{~mm}$ EGTA (right), on changing the prepulse potential from -80 to $-50 \mathrm{mV}$. B, Average data showing the sensitivity of the mean autoreceptor current charge at a fixed prepulse potential $(-80 \mathrm{mV})$ as a function of EGTA concentration. Note the weak potency of EGTA as a blocker of exocytosis. Even at $30 \mathrm{~mm}$, the reduction of the autoreceptor amplitude with respect to the control data (50 $\mu \mathrm{M}$ EGTA) was not statistically significant. C, Average data from experiments as in $\boldsymbol{A}$, showing significant $(p<0.05)$ increases in autoreceptor current amplitude on prepulse depolarization with $0.05,1$, or $10 \mathrm{~mm}$ EGTA, but not with $30 \mathrm{~mm}$ EGTA.D. Fluorescence axonal responses to depolarizing voltage pulses without or with $10 \mathrm{~mm}$ EGTA, showing that EGTA abolishes the voltage dependence of the OGB-1 signal. $E$, Summary data of the EGTA experiments. Error bars indicate SEM.

\section{Depolarization-induced facilitation depends on protein kinase $\mathrm{C}$ activation}

The results obtained so far suggest that activation of voltagedependent $\mathrm{Ca}^{2+}$ channels is responsible for the depolarizationinduced facilitation in GABA release, but they fail to specify the link between the two phenomena. One possible intermediate is PKC since, after repetitive presynaptic stimulation, residual increase in the presynaptic $\mathrm{Ca}^{2+}$ concentration activates PKC, leading to posttetanic potentiation (Brager et al., 2003; Korogod et al., 2007). To test the possible role of PKC in our system, we first tested the effects of the PKC activator PDBu. Application of $1 \mu \mathrm{M}$ PDBu increased the charge carried by the autoreceptor current by $64 \pm 21 \%(n=9$; paired $t$ test, $p<0.05$; data obtained with prepulses at $-80 \mathrm{mV}$ ). These data suggest that GABA release in MLI terminals is sensitive to PKC activation and that PKCinduced facilitation of GABA release is strong enough to underlie depolarization-induced facilitation of GABA release.

However, phorbol esters can enhance neurotransmitter release independently of PKC (Brose and Rosenmund, 2002). To ascertain whether the effect of PDBu was mediated by PKC, we investigated the effects of the PKC blocker Ro 31-8220. Effects of somatic depolarization were assessed on axonal $\mathrm{Ca}^{2+}$ concentration and autoreceptor currents. Because the blocking action of Ro 31-8220 develops slowly in slices (Korogod et al., 2007), the ex- periments were performed alternatively on slices that had been incubated $>1 \mathrm{~h}$ in the presence of $3 \mu \mathrm{M}$ Ro 31-8220, and on control slices that had been incubated in identical conditions but in the absence of Ro 31-8220. Three parameters indicated a decrease in GABA release in the presence of Ro 31-8220. The amplitude of the autoreceptor current measured at $-60 \mathrm{mV}$ was on average reduced (from $62.1 \pm 10.1 \mathrm{pA}, n=17$ in control, to $42.1 \pm 7.7 \mathrm{pA}, n=15$ in Ro 31-8220) (Fig. 8 Bb). In addition, the frequency and amplitude of spontaneous GPSCs were reduced (frequency: $2.03 \pm 0.39 \mathrm{~Hz}, n=5$ in control, vs $1.50 \pm 0.33 \mathrm{~Hz}$, $n=6$ in Ro; amplitude: $69.6 \pm 10.9 \mathrm{pA}, n=5$ in control, vs $34.7 \pm 4.2 \mathrm{pA}, n=6$ in Ro; $p<0.05$, unpaired $t$ test) (Fig. 8 , compare $A a, A b)$. The first and second effect did not reach statistical significance, but the third did, and collectively these measurements indicate the presence of a tonic facilitation by the PKC pathway. We found that Ro 31-8220 incubation did not prevent the $\mathrm{Ca}^{2+}$ concentration increase elicited by somatic depolarization (Fig. $8 \mathrm{Bc}$ ), and that it did not alter significantly the amount of entry elicited by an action potential (Fig. $8 B d$ ), but that it blocked entirely the effect of prepulse depolarization on the autoreceptor current amplitude (Fig. $8 \mathrm{Ba}$ ). These results indicate that $\mathrm{PKC}$ acts downstream of $\mathrm{Ca}^{2+}$ and that it is responsible for linking the increase in the presynaptic basal $\mathrm{Ca}^{2+}$ concentration to an increase in the release probability.

\section{Discussion}

\section{Analog signaling in MLIs}

Whereas previous publications indicated that somatic depolarization enhances action potential-independent GABA release in MLIs [miniature currents (Glitsch and Marty, 1999) as well as "preminis" (Trigo et al., 2010)], the present work demonstrates a similar effect for action potential-dependent release. Together, these studies firmly establish the presence of analog signaling in MLIs, and they show that analog signaling is not restricted to glutamatergic synapses. Both autoreceptor currents and postsynaptic currents obtained in connected pairs were modulated, with similar ratio values between -80 and $-50 \mathrm{mV}(\sim 1.8$ - and 1.5 fold, respectively). The somewhat larger voltage-dependent potentiation found for autoreceptors compared with synaptic currents may be explained by a higher weight of proximal release sites in the first case (Pouzat and Marty, 1999).

\section{Role of calcium in analog signaling}

We find that a step somatic depolarization leads to a slow increase of the basal axonal $\mathrm{Ca}^{2+}$ concentration. Three pieces of evidence indicate that this effect is linked to analog signaling. First, blocking voltage-dependent $\mathrm{Ca}^{2+}$ channels with cadmium inhibits both the axonal $\mathrm{Ca}^{2+}$ rise (this study) and somatically induced increases in axonal GABA release as measured with premini frequency (Trigo et al., 2010). Second, as shown in the present work, the onset kinetics of somatically driven autoreceptor current potentiation is identical with those of the rise in basal axonal $\mathrm{Ca}^{2+}$ concentration. Third, as further discussed below, analog signaling is under the control of the $\mathrm{Ca}^{2+}$-sensitive kinase PKC. Based on these data, we propose that axonal $\mathrm{Ca}^{2+}$ changes underlie analog signaling in MLIs. This mechanism is consistent with results at the calyx of Held in which a step presynaptic depolarization induces a slow increase both of the basal presynaptic $\mathrm{Ca}^{2+}$ concentration and of the release probability (Awatramani et al., 2005). Likewise, in axons of cortical pyramidal neurons, somatically triggered $\mathrm{Ca}^{2+}$ rises have a time course on the order of $1 \mathrm{~s}$ (Yu et al., 2010). In granule cells of the dentate gyrus, however, 
A a

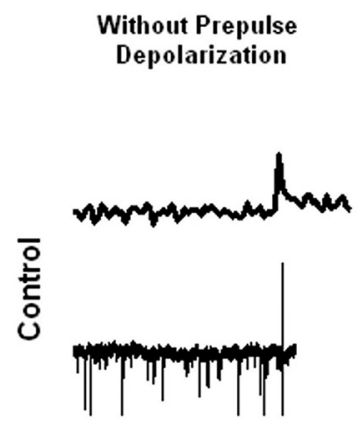

b

B

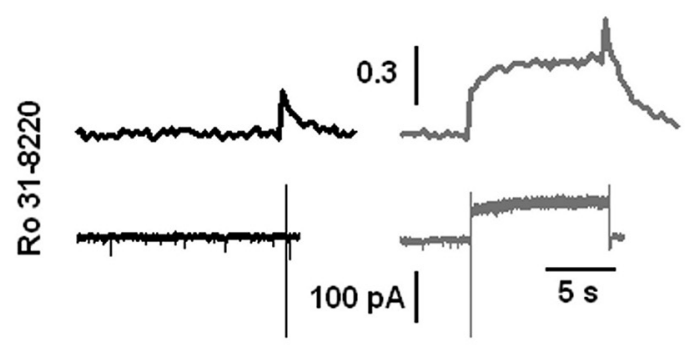

a

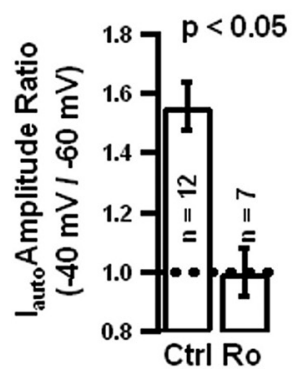

b

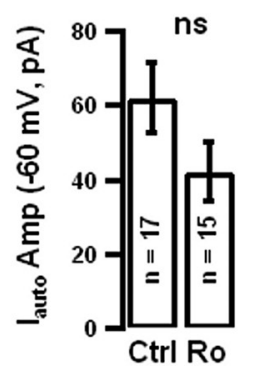

10 s Prepulse

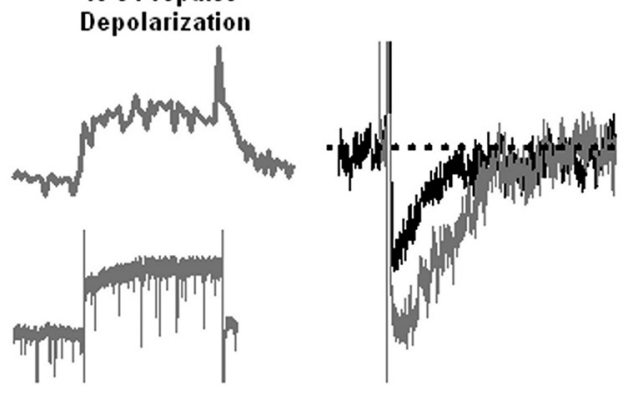

The simplest way to reconcile these apparent contradictions is to hypothesize two parallel pathways that would contribute to analog signaling in various proportions in different preparations (Scott et al., 2008): the purely $\mathrm{Ca}^{2+}$-dependent pathway described in the present work, and an additional pathway that would lead to an increased action potential-driven $\mathrm{Ca}^{2+}$ recruitment after either presynaptic depolarization or presynaptic basal $\mathrm{Ca}^{2+}$ increase.

\section{Source of calcium during analog signaling}

$\mathrm{P} / \mathrm{Q}$ type channels are primarily responsible for depolarization-induced $\mathrm{Ca}^{2+}$ entry. These results are in line both with previous pharmacological results on depolarizationinduced $\mathrm{Ca}^{2+}$ signals [both at the calyx of Held (Awatramani et al., 2005) and in cortical neurons (Yu et al., 2010)] and with the known blocker sensitivity of action potential-induced axonal $\mathrm{Ca}^{2+}$ transients in MLIs (Forti et al., 2000). Even though P/Q channels belong to the high-threshold $\mathrm{Ca}^{2+}$ channel family, their voltage sensitivity may be enhanced in axons because of the association of specific binding proteins (Dolphin, 2009). In addition, even a very modest entry occurring at the foot of the voltage activation curve may be sufficient to accumulate $\mathrm{Ca}^{2+}$ with time (Awatramani et al., 2005). It is important in this regard to note that analog signaling and action potential-driven transmitter release operate on totally different time and space domains. Whereas action potential-induced $\mathrm{Ca}^{2+}$ transients are rapid and local, each varicosity giving rise to a distinct signal (Forti et al., 2000), the depolarization-induced $\mathrm{Ca}^{2+}$ rise is both slow and global. Transmission of the somatic depolarization to the axon by passive membrane properties is expected to occur on a timescale of a few milliseconds, not seconds (Mejia-Gervacio et al., 2007), and would thus be unable to account for the slow rise time of the axonal $\mathrm{Ca}^{2+}$ concentration. Under these circumstances, the slow time course of the signal is best ex-

somatic depolarization is able to increase much more rapidly the release probability at axonal sites [after $\sim 10 \mathrm{~ms}$ instead of a few seconds (Alle and Geiger, 2006)]. Furthermore, in the same preparation, the basal $\mathrm{Ca}^{2+}$ concentration is not affected by somatic depolarization (Scott et al., 2008).

It has been proposed that part or all of the somatically driven potentiation could be attributable to an increase in action potential-induced $\mathrm{Ca}^{2+}$ entry, either after a modification in the shape of the action potential [in cortical neurons (Shu et al., 2006)] or through a change in the properties of $\mathrm{Ca}^{2+}$ channels [at the calyx of Held (Hori and Takahashi, 2009)]. In the present preparation, however, analog potentiation was not associated with any significant change in the depolarization-induced $\mathrm{Ca}^{2+}$ rise that is elicited by single action potentials. plained by the time taken to fill the axonal compartment with a small but persistent $\mathrm{Ca}^{2+}$ entry.

In hippocampal granule cells, single EPSPs are able to significantly enhance glutamate release of the recipient cell over a period of tens of milliseconds (Alle and Geiger, 2006). By contrast, in MLIs, the slow kinetics of the axonal $\mathrm{Ca}^{2+}$ concentration and associated change in release probability preclude an immediate effect of individual synaptic potentials on GABA release. However, in certain conditions [for example, after activation of metabotropic glutamate receptors (Collin et al., 2009)], MLIs are able to fire in bursts, with long (several seconds) up states alternating with down states. Under such conditions, analog signaling is expected to contribute to enhance synaptic transmission during the up states. 


\section{Role of PKC in analog signaling}

Our results show that analog signaling in MLIs is enhanced by phorbol esters and blocked by a PKC inhibitor. Phorbol esters can enhance exocytosis independently of PKC (Brose and Rosenmund, 2002; Lou et al., 2008), but in the present case the most parsimonious scheme suggested by available evidence is a chain of events comprised of $\mathrm{Ca}^{2+}$ entry, subsequent $\mathrm{PKC}$ activation, and $\mathrm{PKC}$-induced phosphorylation of one or several proteins favoring exocytosis. The weak sensitivity of analog signaling in MLIs to EGTA suggests that PKC is closely associated to the $\mathrm{Ca}^{2+}$ channels responsible for $\mathrm{Ca}^{2+}$ entry and that the entire process could be very local. PKC is activated by diacylglycerol through binding to its $\mathrm{C} 1$ domain or directly by $\mathrm{Ca}^{2+}$ via its $\mathrm{C} 2$ domains and has been found to induce synaptic potentiation/augmentation in many studies (for review, see Majewski and Iannazzo, 1998). Munc18-1 is essential for presynaptic vesicle release (Verhage et al., 2000) and is rapidly phosphorylated by PKC on depolarization (de Vries et al., 2000). This makes Munc18-1 a plausible downstream target of the PKC-dependent potentiation described here.

More work will be needed to identify the rate-limiting step that is responsible for the kinetics of the release probability change after a step change in axonal potential. Because EGTA blocks more efficiently the axonal calcium rise than the change in release probability, the relevant calcium signal may be quicker than the measured bulk calcium change, and steps downstream of calcium may be rate limiting, such as PKC activation or phosphorylation of a target protein.

\section{Interactions between analog signaling and activation of presynaptic $\mathrm{GABA}_{\mathrm{A}} \mathrm{Rs}$}

It is striking that in several preparations in which the mechanisms of analog signaling have been studied, presynaptic terminals bear $\mathrm{GABA}_{\mathrm{A}}$ Rs or glycine receptors [calyx of Held (Turecek and Trussell, 2001); mossy fiber terminals (Ruiz et al., 2003; Alle and Geiger, 2007); MLIs (Pouzat and Marty, 1999; Trigo et al., 2007)]. Activation of presynaptic $\mathrm{GABA}_{\mathrm{A}}$ Rs or glycine receptors results in presynaptic depolarization, in an elevation of the axonal $\mathrm{Ca}^{2+}$ concentration, and in enhanced transmitter release (for review, see Trigo et al., 2008). Thus, it is likely that presynaptic $\mathrm{GABA}_{\mathrm{A}} \mathrm{R}$ or glycine receptor activation and analog signaling share common pathways and that they interact extensively with each other.

Under resting conditions, axonal $\mathrm{GABA}_{\mathrm{A}}$ Rs of MLIs are tonically activated, resulting in an enhancement of GABA release (Trigo et al., 2007). When applying a paired-pulse protocol, the paired-pulse ratio is decreased by activation of presynaptic $\mathrm{GABA}_{\mathrm{A}}$ Rs (Trigo et al., 2007). This suggests that the $\mathrm{GABA}_{\mathrm{A}} \mathrm{R}$ induced potentiation is integrated in time and is not phasic, since if it were phasic, the effect of the first pulse of a pair would be to increase the amplitude of the second GPSC and thus increase the paired-pulse ratio. The PKC pathway suggested here for analog signaling provides a mechanistic basis for such an integrated phenomenon since it implies a slow metabolic step that is likely to spread out in time the influence of the $\mathrm{Ca}^{2+}$ signal on the release probability at the MLI-MLI synapse.

\section{References}

Alle H, Geiger JR (2006) Combined analog and action potential coding in hippocampal mossy fibers. Science 311:1290-1293.

Alle H, Geiger JR (2007) GABAergic spill-over transmission onto hippocampal mossy fiber boutons. J Neurosci 27:942-950.

Alle H, Geiger JR (2008) Analog signalling in mammalian cortical axons. Curr Opin Neurobiol 18:314-320.

Awatramani GB, Price GD, Trussell LO (2005) Modulation of transmitter release by presynaptic resting potential and background calcium levels. Neuron 48:109-121.

Brager DH, Cai X, Thompson SM (2003) Activity-dependent activation of presynaptic protein kinase $\mathrm{C}$ mediates post-tetanic potentiation. Nat Neurosci 6:551-552.

Brose N, Rosenmund C (2002) Move over protein kinase C, you've got company: alternative cellular effectors of diacylglycerol and phorbol esters. J Cell Sci 115:4399-4411.

Bucurenciu I, Kulik A, Schwaller B, Frotscher M, Jonas P (2008) Nanodomain coupling between $\mathrm{Ca}^{2+}$ channels and $\mathrm{Ca}^{2+}$ sensors promotes fast and efficient transmitter release at a cortical GABAergic synapse. Neuron 57:536-545.

Chavas J, Marty A (2003) Coexistence of excitatory and inhibitory GABA synapses in the cerebellar interneuron network. J Neurosci 23:2019-2031.

Christie JM, Jahr CE (2008) Dendritic NMDA receptors activate axonal calcium channels. Neuron 60:298-307.

Collin T, Chat M, Lucas MG, Moreno H, Racay P, Schwaller B, Marty A, Llano I (2005) Developmental changes in parvalbumin regulate presynaptic $\mathrm{Ca}^{2+}$ signaling. J Neurosci 25:96-107.

Collin T, Franconville R, Ehrlich BE, Llano I (2009) Activation of metabotropic glutamate receptors induces periodic burst firing and concomitant cytosolic $\mathrm{Ca}^{2+}$ oscillations in cerebellar interneurons. J Neurosci 29:9281-9291.

De Crescenzo V, Fogarty KE, Zhuge R, Tuft RA, Lifshitz LM, Carmichael J, Bellvé KD, Baker SP, Zissimopoulos S, Lai FA, Lemos JR, Walsh JV Jr (2006) Dihydropyridine receptors and type 1 ryanodine receptors constitute the molecular machinery for voltage-induced $\mathrm{Ca}^{2+}$ release in nerve terminals. J Neurosci 26:7565-7574.

de Vries KJ, Geijtenbeek A, Brian EC, de Graan PN, Ghijsen WE, Verhage M (2000) Dynamics of munc18-1 phosphorylation/dephosphorylation in rat brain nerve terminals. Eur J Neurosci 12:385-390.

Dolphin AC (2009) Calcium channel diversity: multiple roles of calcium channel subunits. Curr Opin Neurobiol 19:237-244.

Forti L, Pouzat C, Llano I (2000) Action potential-evoked $\mathrm{Ca}^{2+}$ signals and calcium channels in axons of developing rat cerebellar interneurones. J Physiol 527:33-48.

Geiger JR, Jonas P (2000) Dynamic control of presynaptic $\mathrm{Ca}^{2+}$ inflow by fast-inactivating $\mathrm{K}^{+}$channels in hippocampal mossy fiber boutons. Neuron 28:927-939.

Glitsch M, Marty A (1999) Presynaptic effects of NMDA in cerebellar Purkinje cells and interneurons. J Neurosci 19:511-519.

Hori T, Takahashi T (2009) Mechanisms underlying short-term modulation of transmitter release by presynaptic depolarization. J Physiol 587:2987-3000

Kondo S, Marty A (1998) Synaptic currents at individual connections among stellate cells in rat cerebellar slices. J Physiol 509:221-232.

Korogod N, Lou X, Schneggenburger R (2007) Posttetanic potentiation critically depends on an enhanced $\mathrm{Ca}^{2+}$ sensitivity of vesicle fusion mediated by presynaptic PKC. Proc Natl Acad Sci U S A 104:15923-15928.

Llano I, Tan YP, Caputo C (1997) Spatial heterogeneity of intracellular $\mathrm{Ca}^{2+}$ signals in axons of basket cells from rat cerebellar slices. J Physiol 502:509-519.

Llano I, González J, Caputo C, Lai FA, Blayney LM, Tan YP, Marty A (2000) Presynaptic calcium stores underlie large-amplitude miniature IPSCs and spontaneous calcium transients. Nat Neurosci 3:1256-1265.

Lou X, Korogod N, Brose N, Schneggenburger R (2008) Phorbol esters modulate spontaneous and $\mathrm{Ca}^{2+}$-evoked transmitter release via acting on both Munc13 and protein kinase C. J Neurosci 28:8257-8267.

Majewski H, Iannazzo L (1998) Protein kinase C: a physiological mediator of enhanced transmitter output. Prog Neurobiol 55:463-475.

Mejia-Gervacio S, Collin T, Pouzat C, Tan YP, Llano I, Marty A (2007) Axonal speeding: shaping synaptic potentials in small neurons by the axonal membrane compartment. Neuron 53:843-855.

Neher E, Augustine GJ (1992) Calcium gradients and buffers in bovine chromaffin cells. J Physiol 450:273-301.

Nicholls J, Wallace BG (1978) Modulation of transmission at an inhibitory synapse in the central system of the leech. J Physiol 281:157-170.

Pouzat C, Marty A (1999) Somatic recording of GABAergic autoreceptor current in cerebellar stellate and basket cells. J Neurosci 19:1675-1690.

Ruiz A, Fabian-Fine R, Scott R, Walker MC, Rusakov DA, Kullmann DM (2003) $\mathrm{GABA}_{\mathrm{A}}$ receptors at hippocampal mossy fibers. Neuron 39:961-973

Scott R, Ruiz A, Henneberger C, Kullmann DM, Rusakov DA (2008) Analog 
modulation of mossy fiber transmission is uncoupled from changes in presynaptic $\mathrm{Ca}^{2+}$. J Neurosci 28:7765-7773.

Shimahara T, Tauc L (1975) Multiple interneuronal afferents to the giant cells in Aplysia. J Physiol 247:299-319.

Shu Y, Hasenstaub A, Duque A, Yu Y, McCormick DA (2006) Modulation of intracortical synaptic potentials by presynaptic somatic membrane potential. Nature 441:761-765.

Smith TC, Jahr CE (2002) Self-inhibition of olfactory bulb neurons. Nat Neurosci 5:760-766.

Southan AP, Morris NP, Stephens GJ, Robertson B (2000) Hyperpolarizationactivated currents in presynaptic terminals of mouse cerebellar basket cells. J Physiol 526:91-97.

Trigo FF, Chat M, Marty A (2007) Enhancement of GABA release through endogenous activation of axonal $\mathrm{GABA}_{\mathrm{A}}$ receptors in juvenile cerebellum. J Neurosci 27:12452-12463.
Trigo FF, Marty A, Stell BM (2008) Axonal GABA $A_{A}$ receptors. Eur J Neurosci 28:841-848.

Trigo FF, Bouhours B, Rostaing P, Papageorgiou G, Corrie JE, Triller A, Ogden D, Marty A (2010) Presynaptic miniature GABAergic currents in developing interneurons. Neuron 66:235-247.

Turecek R, Trussell LO (2001) Presynaptic glycine receptors enhance transmitter release at a mammalian central synapse. Nature 411: 587-590.

Verhage M, Maia AS, Plomp JJ, Brussaard AB, Heeroma JH, Vermeer H, Toonen RF, Hammer RE, van den Berg TK, Missler M, Geuze HJ, Südhof TC (2000) Synaptic assembly of the brain in the absence of neurotransmitter secretion. Science 287:864-869.

Yu Y, Maureira C, Liu X, McCormick D (2010) P/Q and N channels control baseline and spike-triggered calcium levels in neocortical axons and synaptic boutons. J Neurosci 30:11858-11869. 